\title{
Cognitive trajectories in multiple sclerosis: a long-term follow-up study
}

\author{
Antonio Carotenuto ${ }^{1}$ (D) Teresa Costabile $^{1}$. Giuseppe Pontillo ${ }^{2} \cdot$ Moccia Moccia $^{1}$ - Fabrizia Falco ${ }^{1} \cdot$ Maria Petracca $^{1}$. \\ Martina Petruzzo ${ }^{1}$. Cinzia Valeria Russo ${ }^{1}$ - Martina Di Stasi ${ }^{2} \cdot$ Chiara Paolella $^{2}$. Teresa Perillo ${ }^{2}$. Elena Augusta Vola ${ }^{2}$. \\ Maria Brunella Cipullo ${ }^{2}$. Sirio Cocozza ${ }^{2} \cdot$ Roberta Lanzillo $^{1} \cdot$ Vincenzo Brescia Morra $^{1} \cdot$ Francesco Saccà $^{1}$
}

Received: 1 March 2021 / Accepted: 28 May 2021 / Published online: 8 June 2021

(c) The Author(s) 2021

\begin{abstract}
Background Cognitive impairment occurs in multiple sclerosis (MS) and undergoes a progressive worsening over disease course. However, clinicians still struggle to predict the course of cognitive function. To evaluate baseline clinical and imaging predictors of cognitive abilities worsening over time, we performed a latent trajectory analysis for cognitive performances in MS patients, up to 15 years from disease onset.

Methods We collected age, sex, education, dominant and non-dominant 9-hole peg test (9HP) and timed 25-foot walk (T25-FW) as well as MRI measures (grey matter volume and lesion load) within 6 months from disease diagnosis for relapsing-remitting MS (RR-MS) patients. At diagnosis and over the follow-up, we also assessed cognitive status through the symbol digit modalities test (SDMT). Cognitive impairment was defined by applying age-, gender- and education-adjusted normative values. Group-based trajectory analysis was performed to determine trajectories, and the predictive value of clinical and imaging variables at baseline was assessed through multinomial logistic regression.

Results We included 148 RR-MS (98 females and 50 males). Over $11 \pm 4$ year follow-up, $51.4 \%$ remained cognitively stable whereas $48.6 \%$ cognitively worsened. Cognitively worsening patients had a higher T25FW time $(p=0.004)$ and a reduced hippocampal volume at baseline $(p=0.04)$.

Conclusion Physical disability as well as hippocampal atrophy might depict patients at risk of cognitive worsening over the disease course. Therefore, using such predictors, clinicians may select patients to carefully evaluate for cognitive impairment as to eventually introduce cognitive rehabilitation treatments.
\end{abstract}

Keywords Cognitive dysfunction · Hippocampus · Biomarkers · Magnetic resonance imaging $\cdot$ Disability predictors · Longitudinal data analysis

\section{Introduction}

Brescia Morra Vincenzo, Saccà Francesco equally contributed as senior authors.

Antonio Carotenuto

carotenuto.antonio87@gmail.com;

antonio.carotenuto@unina.it

1 Department of Neurosciences, Reproductive and Odontostomatological Sciences, Federico II University, Naples, Italy

2 Department of Advanced Biomedical Sciences, Federico II University, Naples, Italy
Cognition can be impaired in up to $70 \%$ multiple sclerosis (MS) patients from disease onset [1], mostly affecting attention, information processing speed and long-term memory [2] with a negative impact on everyday activities [3]. Lesion load and global and regional brain atrophy, together with microstructural changes throughout the brain, are associated with deficits in cognition for MS patients in cross-sectional studies $[4,5]$. Over the disease course, cognitive function might further worsen [6]. However, clinicians still struggle to predict whether a patient will deteriorate in terms of cognitive abilities over the long-term follow-up due to the lack of baseline reliable predictive biomarkers. Available longitudinal studies showed that increased lesion load and 
grey and white matter atrophy are associated with cognitive worsening in MS [7-11]. Baseline measures such as grey matter volume, temporal atrophy, diffuse microstructural changes and, specifically, microstructural alterations in the anterior thalamic radiations and the superior longitudinal fasciculus might predict cognitive outcome in MS up to 7 years from disease onset [11, 12]. However, in order to better tailor disease management and treatment strategies at disease diagnosis, taking into account also the possibility of cognitive deterioration over time with subsequent negative impact on social life, predictive biomarkers for long-term cognitive outcome in MS are extremely needed.

Group-based trajectory analysis is a statistical approach allowing to identify and summarize complex patterns in longitudinal data assuming that the sample is composed of a mixture of different groups following similar longitudinal trends for a specific variable [13]. Initially, this approach was applied in psychology [14] and criminology [15], but only recently it was applied also in medicine, especially for evaluating cognitive trajectories in people with mild cognitive impairment $[16,17]$. Hereby, we aim at classifying longterm longitudinal cognitive trajectories of MS patients using the group-based trajectories analysis. Moreover, we also aim to evaluate the demographic, clinical and imaging measures predicting cognitive worsening over long-term follow-up.

\section{Methods}

\section{Study design}

This is a retrospective study including newly diagnosed relapsing-remitting MS subjects (RR-MS), with cognitive assessment at diagnosis that have been followed up prospectively up to 15 years.

\section{Subject enrolment}

We included subjects receiving a new diagnosis of RR-MS from January 2004 to January 2012 at the 'Federico II' University (Naples, Italy).

Inclusion criteria were (i) diagnosis of RR-MS according to 2001,2006 or 2010 McDonald's criteria as appropriate [18-20] and (ii) $\leq 6$ months from disease diagnosis. Exclusion criteria were past or present systemic medical conditions or psychiatric diseases or treatments that might impact on cognitive performances (i.e. chemotherapy, or corticosteroid treatment from less than 1 month).

Exclusion criteria were past or present systemic medical conditions or psychiatric diseases.

Sociodemographic (age, gender and education) and clinical data (age at onset, disease duration, EDSS, 9-hole peg board test for dominant [9HP-D] and non-dominant hand [9HP-ND] and Timed 25-Foot Walk [T25-FW], global annualized relapse rate calculated as total number of relapse before enrolment over disease duration from disease onset) were collected at baseline. MS subjects were treated with different disease-modifying treatments (DMTs), possibly changed or discontinued during the study period as for clinical practice. DMTs including interferonbeta, glatiramer acetate, dimethylfumarate and teriflunomide were classified as first line, while all other DMTs were classified as second-line DMTs. Changes in DMTs, the occurrence of phenotype conversion from RR-MS to secondary progressive MS (SPMS), following clinical diagnosis, and the occurrence of relapses over the followup were recorded. Follow-up visits were scheduled as for clinical practice (mostly every 6 months or on the occasion of relapses).

\section{Neuropsychological assessments}

Cognitive function at baseline was assessed within 6 months from disease onset through the Symbol Digit Modalities Test (SDMT) [21]. SDMT rough scores were age, gender and education corrected by applying the available normative values and cognitive impairment was defined if the corrected scores fell below the 5th percentile [22, 23]. Only patients with at least three different cognitive assessments (including the baseline assessment) were enrolled in the study.

\section{MRI data acquisition and analysis}

MRI scans were acquired at baseline on $3 \mathrm{~T}$ scanner (Trio, Siemens Medical Systems, Erlangen, Germany), with the acquisition protocol including a 3D T1-weighted magnetization-prepared rapid acquisition gradient echo sequence (MPRAGE; TR $=1900 \mathrm{~ms} ; \mathrm{TR}=3.39 \mathrm{~ms} ; \mathrm{TE}=3.4 \mathrm{~ms}$; $\mathrm{TI}=900 \mathrm{~ms}$; flip angle $=9^{\circ}$; voxel size $=1 \times 1 \times 1 \mathrm{~mm}^{3}$; field of view $=250 \times 250 ; 160$ axial slices) and a fluid-attenuated inversion recovery sequence (FLAIR; TR $=9620 \mathrm{~ms}$; $\mathrm{TE}=30 \mathrm{~ms} ; \mathrm{TI}=2500 \mathrm{~ms}$; field of view $=250 \times 250$; voxel size $=1 \times 1 \times 3 \mathrm{~mm}^{3} ; 48$ axial slices).

For the determination of brain volume measurements, hyperintense lesions on FLAIR images were identified and segmented using a semiautomatic approach (Jim 7, Xinapse Systems, Northants, UK). Then, to correct for the possible impact of white matter (WM) lesions on volume measurements, the resulting lesion masks were co-registered via affine registration to the MPRAGE, and masked-out. From lesion masked MPRAGE images, grey matter (GM) and normal appearing WM (NAWM) volumes were estimated with FSL's Structural Image Evaluation Using Normalization of Atrophy (SIENAX) [24], and the normalized brain volume (NBV) was 
calculated summing GM and WM volumes and multiplying such value for the SIENAX scaling factor. Furthermore, subcortical GM volumes were also obtained, using the FIRST routine (FMRIB's Integrated Registration Segmentation Toolkit http://fsl.fmrib.ox.ac.uk/fsl/fslwiki/FIRST) [25], obtaining left and right caudate nucleus, pallidum, putamen, thalamus and hippocampus volumes, which were subsequently averaged. Similarly to the procedure done with the NBV calculation, deep GM volumes were also normalized by multiplying for the SIENAX scaling factor.

\section{Statistical analyses}

Statistical analyses were performed using Stata software (version 13; StataCorp LP, College Station, TX). Demographic, clinical and cognitive features of MS patients were presented as means, medians or proportions as appropriate. Group-based trajectory analysis was carried out using the SAS procedure Proc Traj embedded in STATA [26]. Group-based trajectory analysis identifies latent subgroups from a larger sample with distinct trajectories over time for the outcome measures. Time can vary by person and subjects will be assigned to a specific group based on the largest posterior probability of group membership. Considering MS phenotype and presumptive disease burden over time, models with 2-5 latent subgroups were assessed and the optimal number of subgroups for each outcome measure was defined by selecting the lowest Akaike's information criterion (AIC) [27]. In order to evaluate longitudinal trajectories, we performed a group-based trajectory analysis using a regression model, including SDMT-corrected scores at each time point as dependent variable, disease duration calculated from disease onset as an independent variable, gender, age at onset and annualized relapse rate at diagnosis and EDSS at baseline were examined as time-stable covariates and disease-modifying treatment and the occurrence of relapses were used as time-varying covariates, thus correcting the models for such changes and evaluating their impact on the overall trajectories.

Once membership was assigned, we assessed the predictive value of clinical (9HP-D, 9HP-ND, T25FW and the occurrence of conversion to SPMS) and imaging (normalized cortical grey matter, T2 lesion load, caudate nucleus, pallidum, putamen, thalamus and hippocampus volume) variables at baseline using an ageand gender-adjusted logistic regression. Odds ratio (OR) was reported. We evaluated normal distribution of variables and/or residuals through statistical and graphical approaches. The $p$ value was not corrected for multiple comparisons due to the exploratory nature of the analysis. Results were considered statistically significant for $p<0.05$.

\section{Results}

\section{Baseline features}

We included 148 RR-MS patients (98 females and 50 males). Patients were followed up to $11 \pm 4$ years. Sixty patients underwent MRI scan at baseline. Demographic, clinical and neuroimaging data at enrolment are summarized in Table 1 .

At baseline, 19 out of 148 patients (12.8\%) showed a deficit in SDMT (Table 2). After about 10 years, 36 out of 148 patients (24.3\%) showed a deficit in SDMT.

\section{Cognitive function trajectories}

By comparing the AIC coefficient, we selected the 2 trajectories' model. We depicted MS patients with stable SDMT (76 patients, 51.4\%) and MS patients experiencing SDMT worsening over time (72 patients, $48.6 \%$ ). SDMT trajectories are reported in Fig. 1a. Amid patients classified as cognitively stable, only 2 out of 76 (3\%) showed a SDMT deficit, while for patients classified as cognitively worsened, 34 out of $72(47.2 \%)$ were classified as impaired.

Cognitive worsening over time was predicted by $\mathrm{T} 25 \mathrm{FW}$ and hippocampal volume (OR: $0.25 ; 95 \% \mathrm{CI}=0.10,0.64$; $p=0.004$; and OR: $5.1 ; 95 \% \mathrm{CI}=1.12,22.8 ; p=0.04$, respectively; Fig. 1b, c; Table 3).

\section{Discussion}

In this retrospective study, we investigated cognitive trajectories in a large cohort of RR-MS patients over a long-term follow-up (up to 15 years). We observed that the cognitive function in MS might either remain stable or deteriorate over time. We also pointed out that patients undergoing cognitive worsening over long-term follow-up show a higher degree of motor disability as well as reduced hippocampal volume.

The major novelty of the present study is the data-driven approach to define trajectories based on longitudinal performance, identifying clusters of individuals who have followed a similar developmental trajectory on an outcome of interest $[13,28]$. Differently from other available statistical approaches such as hierarchical modelling and latent curve analysis estimating the population average trajectory, group-based trajectory analysis assumes that the population is made of distinct groups, each one following a different underlying trajectory. Group-based trajectory analysis identifies groups of individuals following similar progressions of some phenomenon over time taking into account the effects of covariates on both trajectory shape and group membership throughout the follow-up period for each single subject. 
Table 1 Demographic, clinical and neuroimaging features at baseline

\begin{tabular}{|c|c|c|}
\hline \multicolumn{3}{|l|}{ Characteristic } \\
\hline Subjects & Total & 148 \\
\hline \multirow[t]{2}{*}{ Sex } & Male, N (\%) & $50(34)$ \\
\hline & Female, $\mathrm{N}(\%)$ & $98(66)$ \\
\hline Age, mean $\pm \mathrm{SD}$ (range) (years) & & $35.1 \pm 8(16-58)$ \\
\hline Age at diagnosis, mean $\pm \mathrm{SD}$ (range) (years) & & $28.4 \pm 7.5(13-45)$ \\
\hline Disease duration from onset, mean $\pm \mathrm{SD}$ (range) (years) & & $6.7 \pm 0.1(0.1-30.9)$ \\
\hline EDSS, median (range) & & $2(1.5-4.5)$ \\
\hline $\mathrm{ARR}$, mean $\pm \mathrm{SD}$ (range) & & $0.94 \pm 0.41(0-2.5)$ \\
\hline Timed 25-foot walk, mean \pm SD (range) & & $5.9 \pm 0.2(5.6-6.3)$ \\
\hline Nine hole peg-board test dominant hand, mean \pm SD (range) & & $20.7 \pm 0.5(19.8-21.6)$ \\
\hline Nine hole peg-board test non dominant hand, mean \pm SD (range) & & $21.8 \pm 0.5(20.7-22.8)$ \\
\hline Follow-up time, mean $\pm \mathrm{SD}$ (Range) (years) & & $11 \pm 4(1-35)$ \\
\hline Number of cognitive assessment over the follow-up, median (range) & & $4(2-5)$ \\
\hline Cortical grey matter (volume), mean $\pm \mathrm{SD}$ & & $756.2 \pm 50.92$ \\
\hline Normal appearing white matter (volume), mean \pm SD & & $667.8 \pm 42.92$ \\
\hline $\mathrm{T} 2$-weighted lesion load (volume), mean $\pm \mathrm{SD}$ & & $7.3 \pm 7.92$ \\
\hline Caudate nucleus (volume), mean $\pm \mathrm{SD}$ & & $3.6 \pm 0.59$ \\
\hline Pallidum (volume), mean \pm SD & & $1.7 \pm 0.22$ \\
\hline Putamen (volume), mean \pm SD & & $4.9 \pm 0.76$ \\
\hline Thalamus (volume), mean \pm SD & & $7.3 \pm 0.9$ \\
\hline Hippocampus (volume), mean \pm SD & & $3.9 \pm 0.5$ \\
\hline
\end{tabular}

$A R R$ annualized relapse rate; $N$ number; $E D S S$ expanded disability status scale; $S D$ standard deviation. All volumes are expressed in milliliters

Table 2 Clinical and cognitive assessments over the follow-up

\begin{tabular}{|c|c|c|c|c|c|c|c|}
\hline Time points & & 1 & 2 & 3 & 4 & 5 & 6 \\
\hline Number of subjects & & 148 & 148 & 148 & 125 & 76 & 33 \\
\hline $\begin{array}{l}\text { Time from baseline cognitive assess- } \\
\text { ment, mean } \pm \mathrm{SD} \text { (years) }\end{array}$ & & - & $1.98 \pm 0.21$ & $9.96 \pm 1.92$ & $11 \pm 1.89$ & $11.42 \pm 1.76$ & $11.93 \pm 1.51$ \\
\hline $\begin{array}{l}\text { Time from previous cognitive assess- } \\
\text { ment, mean } \pm \text { SD (years) }\end{array}$ & & - & $1.98 \pm 0.21$ & $7.96 \pm 1.92$ & $1.12 \pm 0.34$ & $1.09 \pm 0.25$ & $1.04 \pm 0.19$ \\
\hline EDSS, mean \pm SD & & $2.3 \pm 0.7$ & $2.5 \pm 0.8$ & $3.3 \pm 1.1$ & $3.4 \pm 1.3$ & $3.6 \pm 1.6$ & $3.6 \pm 1.4$ \\
\hline$\%$ of patients experiencing a relapse & & - & 33.1 & 59.2 & 4.8 & 3.4 & 0.7 \\
\hline \multirow[t]{3}{*}{ Disease-modifying therapy } & No treatment, $(\%)$ & 62 & 1.4 & 2 & 0.80 & 1.3 & 0 \\
\hline & First line, $(\%)$ & 38 & 97.2 & 76.2 & 62.4 & 44.8 & 42.4 \\
\hline & Second line, $(\%)$ & 0 & 1.4 & 21.8 & 36.8 & 53.9 & 57.6 \\
\hline $\mathrm{SDMT}$, mean $\pm \mathrm{SD}$ & & $50.5 \pm 12.7$ & $45.8 \pm 12.1$ & $43.9 \pm 12$ & $43.7 \pm 11.9$ & $43.6 \pm 11$ & $44.3 \pm 11$ \\
\hline$\%$ of patients failing the test & & 12.8 & 25 & 23.8 & 24 & 23.4 & 27.3 \\
\hline
\end{tabular}

EDSS expanded disability status scale; $S D$ standard deviation; SDMT symbol digit modalities test

Particularly, time-stable covariates influence group membership, while time-dependent covariates explain variation about the average trajectory within each group. For these characteristics, group-based trajectory modelling should be preferred to hierarchical and latent curve modelling when handling non-monotonic trajectories and trajectories that do not vary regularly in the population. Moreover, while raw categorization in stable versus worsening patients only considers the first and last measure, here, we took advantage from the trajectory analysis, providing the unique opportunity to depict the trend for each measure throughout the time span. This might be particularly relevant in disorder such as MS, where fluctuating symptoms like fatigue, anxiety or depression may harshly impact cognitive performance [29]. The importance of such approach was also recently highlighted from Healy et al. who were able to classify patients 
Fig. 1 Cognitive trajectories based on SDMT score from baseline over the follow-up and predictors of cognitive abilities worsening. a We identified 2 cognitive trajectories based on SDMT score: MS patients without SDMT worsening over time (76 patients, $51.4 \%$ ) or who developed SDMT worsening over time (72 patients, $48.6 \%$ ). The probability of belonging to SDMT stable group increases with the b shorter timed 25-foot walk $(p=0.004)$ and $\mathbf{c}$ higher hippocampal volume $(p=0.04)$
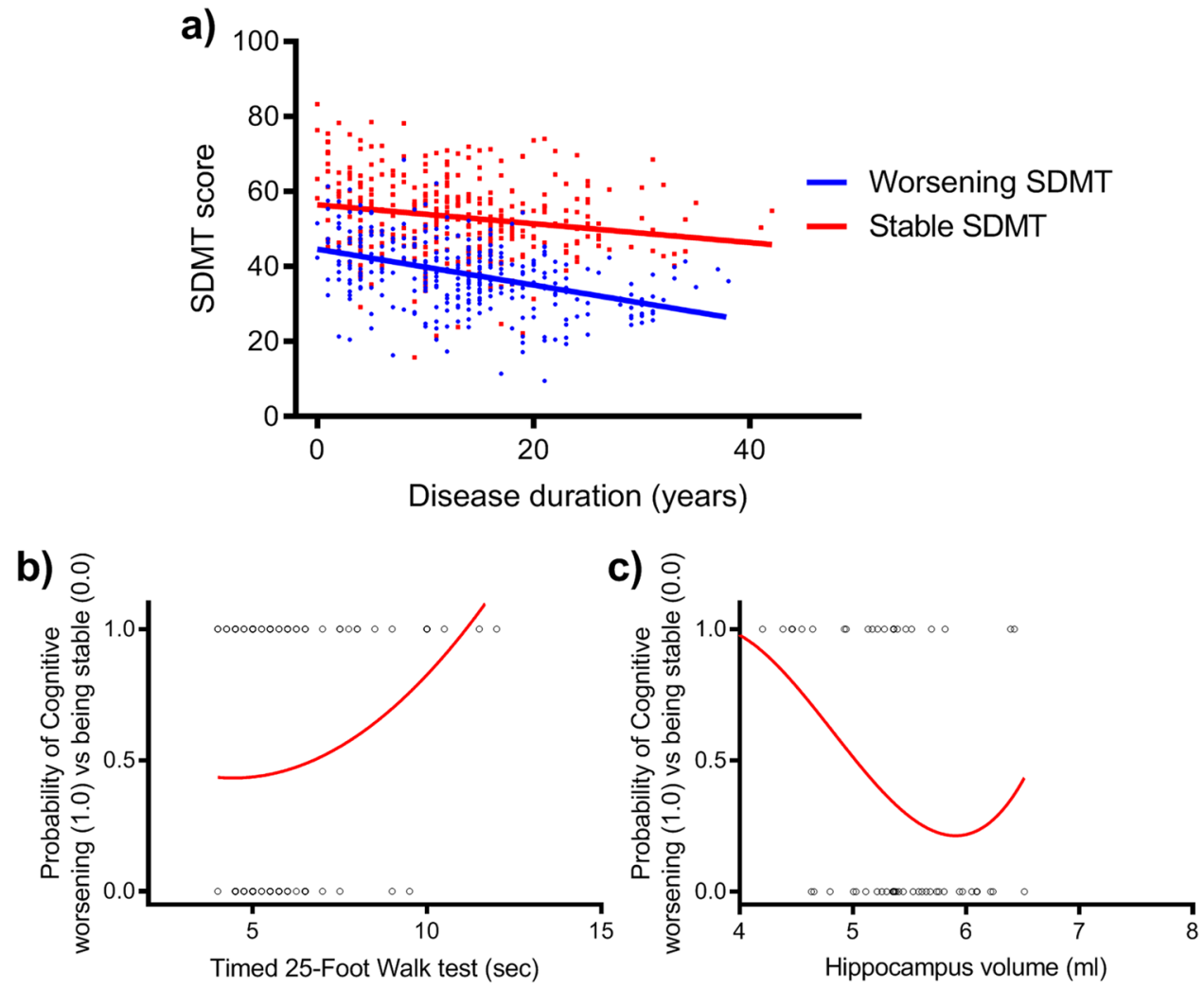

Table 3 Baseline clinical and imaging predictors of cognitive worsening over time

\begin{tabular}{|c|c|c|c|c|c|}
\hline Group & Cognitively stable patients & $\begin{array}{l}\text { Cognitive- } \\
\text { declining } \\
\text { patients }\end{array}$ & OR & $95 \% \mathrm{CI}$ & $p$ value* \\
\hline Number of patients & 76 & 72 & & & \\
\hline 9-hole peg test, dominant hand, mean \pm SD (seconds) & $19.08 \pm 2.79$ & $22.31 \pm 5.89$ & 0.72 & $0.5-1.05$ & 0.19 \\
\hline 9-hole peg test, non-dominant hand, mean \pm SD (seconds) & $20.3 \pm 3.87$ & $23.35 \pm 6$ & 1.19 & $0.88-1.6$ & 0.29 \\
\hline Timed 25-foot walk, mean \pm SD (seconds) & $5.53 \pm 1.07$ & $6.36 \pm 2.04$ & 0.25 & $0.10-0.64$ & $0.004 *$ \\
\hline Normalized cortical grey matter, mean $\pm \mathrm{SD}(\mathrm{ml})$ & $767.26 \pm 49.73$ & $742.61 \pm 49.93$ & 0.95 & $0.86-1.05$ & 0.45 \\
\hline $\mathrm{T} 2$ lesion load, mean $\pm \mathrm{SD}(\mathrm{ml})$ & $8.38 \pm 8.22$ & $12.3 \pm 13.79$ & 1.01 & $0.99-1.03$ & 0.12 \\
\hline Caudate nucleus volume, mean \pm SD $(\mathrm{ml})$ & $4.92 \pm 0.57$ & $5.02 \pm 0.79$ & 0.9 & $0.53-1.07$ & 0.09 \\
\hline Pallidum volume, mean \pm SD (ml) & $2.42 \pm 0.22$ & $2.34 \pm 0.31$ & 3.2 & $0.04-282.12$ & 0.61 \\
\hline Putamen volume, mean \pm SD $(\mathrm{ml})$ & $6.84 \pm 0.66$ & $6.7 \pm 1.14$ & 0.25 & $0.06-1.11$ & 0.07 \\
\hline Thalamus volume, mean $\pm \mathrm{SD}(\mathrm{ml})$ & $10.3 \pm 0.93$ & $9.72 \pm 1.28$ & 0.78 & $0.2-3.07$ & 0.72 \\
\hline Hippocampus volume, mean $\pm \mathrm{SD}(\mathrm{ml})$ & $5.53 \pm 0.46$ & $5.24 \pm 0.84$ & 5.1 & $1.12-22.8$ & $0.035^{*}$ \\
\hline
\end{tabular}

$O R$ odds ratio; $C I$ confidence intervals; $S D$ standard deviation

*Age- and gender-adjusted logistic regression

with SDMT worsening over time using a latent trajectory analysis adjusted for demographic covariates [30]. However, authors did not seek to evaluate baseline predictors of SDMT worsening over time. With this study, we evaluated trajectories for SDMT and we also sought to investigate baseline predictors of cognitive decline. Previous studies report that the proportion of MS patients showing cognitive decline spans from 28 to $70 \%$ [11, 12, 31, 32]. This wide range is mostly due to the number tests/domains explored and also to the different definitions of cognitive decline. Here, we found that $48.7 \%$ of MS patients deteriorated over a long-term follow-up. Although this proportion is in line with previous findings, when considering our longer followup, one would expect a higher rate of cognitive worsening. 
In addition, we should also consider that amid these worsening patients were those contributing the most to SDMT impairment prevalence at follow-up, thus suggesting that trajectories provide a framework of cognitive longitudinal assessment encompassing pre-fixed time points.

Another noteworthy finding of the present study is that we highlighted distinct baseline clinical and radiological features able to predict the overall cognitive outcome. We observed that clinical measures of physical disability evaluating the walking speed is a strong predictors of cognitive decline. Benedict et al. already reported a close interplay between motor abilities and the information processing speed cognitive function in MS patients [33], and speculated that motor functions also depend upon intact cognition since the planning and the performance of the action require cognitive abilities such as attention and executive function [33]. The close interplay between motor abilities and cognitive functions in MS might depend upon the disruption of shared cortico-subcortical networks and cortical pathology. We might hypothesize that reduced walking speed at disease onset in patients developing cognitive impairment at follow-up reflects the presence of tissue microstructural changes and functional network disruption. This damage at baseline may not foster cognitive impairment, but predicts decline over time in cognitive functions, especially for information processing speed. Supporting this point, we also highlighted that hippocampal atrophy at baseline is associated with cognitive decline. Atrophy of the temporal lobe was already associated with cognitive decline in MS patients [12]. Recently, Eijlers and colleagues reported that cognitive decline was predicted by white matter integrity and deep grey matter volume in early stages of MS, whereas cortical atrophy leads to cognitive decline in more advanced MS patients or progressive MS [12]. A study conducted from the same study group pointed out that while cognitive decline is strongly associated with cortical neurodegeneration in progressive stages of the disorder and with deep grey matter atrophy in RR-MS patients converting to progressive stages, white matter damage leads to a slower cognitive worsening in stable RR-MS patients [34]. In our sample, we demonstrated that RR-MS patients, who will develop cognitive impairment over the long-term follow-up, already show reduced hippocampal volume. Previous studies reported an association between hippocampal atrophy and cognitive impairment in cross-sectional studies [35, 36]. Indeed, the fact that declining patients display atrophy even in the absence of cognitive impairment at baseline might suggest that MRI measures we adopted actually depict an ongoing pathological processes that will only subsequently impact clinically relevant measures such as cognitive impairment. One possible missing piece of the puzzle generating this clinical-radiological paradox might be the patients' cognitive reserve, which is the ability of the brain to cope with damages compensatory mechanisms not necessarily related with brain volume but also with brain functioning. Cognitive reserve strongly depends, among the other factors, upon patient's lifestyle, education and social activities [37]. In light with this finding, it is worth exploring the impact of cognitive rehabilitation treatment on cognitive outcome, as several reports have confirmed the efficacy of these treatments on cognitive symptoms [38, 39]. These treatments may either be based on training exercises to improve specific cortical functions or may be delivered through non-invasive brain stimulation aimed at foster brain activity over specific cortical and subcortical grey matter regions [40].

We do acknowledge that this study is not without limitation. Firstly, the lack of a control group prevents us to draw any final conclusion about the disease-specific cognitive worsening. We are aware that cognitive scores may reduce over the follow-up due to aging. However, in the attempt to overcome this issue, we did use the normative age- and gender-corrected scores. Similarly, the lack of the control group may also affect MRI results interpretation. Therefore, future longitudinal studies including $\mathrm{HC}$ group are highly recommended. Secondly, also depression and fatigue may impact on cognitive scores. The lack of such measures did not allow us to correct cognitive scores for neuropsychiatric features.

In conclusion, physical disability as assessed through T25FW as well as MRI measures might depict patients at risk of cognitive decline. Since cognitive impairment correlates with neurodegeneration and harshly affects patient's quality of life, proxies for cognitive deterioration over time should lead clinicians to tailored treatment choices and rehabilitation planning. However, further longitudinal long-term follow-up studies aiming at evaluating not only cognitive but also brain atrophy trajectories could better elucidate the underlying interplay between cognitive reserve, brain pathology and both physical and cognitive disability accrual.

Authors' contributions Carotenuto Antonio, Costabile Teresa, Saccà Francesco: design and concept of the study; Carotenuto Antonio, Costabile Teresa, Saccà Francesco, Pontillo Giuseppe, Moccia Moccia, Falco Fabrizia, Petracca Maria, Petruzzo Martina, Russo Cinzia Valeria, Di Stasi Martina, Paolella Chiara, Perillo Teresa, Vola Elena Augusta, Cipullo Maria Brunella, Cocozza Sirio, Lanzillo Roberta, Brescia Morra Vincenzo, Saccà Francesco: data acquisition; Carotenuto Antonio, Costabile Teresa, Saccà Francesco, Pontillo Giuseppe, Petracca Maria, Di Stasi Martina, Paolella Chiara, Perillo Teresa, Vola Elena Augusta, Cipullo Maria Brunella, Cocozza Sirio: data analysis; Carotenuto Antonio, Costabile Teresa, Saccà Francesco, Moccia Moccia, Falco Fabrizia, Petracca Maria, Cocozza Sirio, Lanzillo Roberta, Brescia Morra Vincenzo, Saccà Francesco: data interpretation; Carotenuto Antonio, Costabile Teresa, Saccà Francesco: manuscript drafting; Carotenuto Antonio, Costabile Teresa, Saccà Francesco, Pontillo Giuseppe, Moccia Moccia, Falco Fabrizia, Petracca Maria, Petruzzo Martina, Russo Cinzia Valeria, Di Stasi Martina, Paolella Chiara, Perillo Teresa, Vola Elena Augusta, Cipullo Maria Brunella, Cocozza 
Sirio, Lanzillo Roberta, Brescia Morra Vincenzo, Saccà Francesco: manuscript revision.

Funding Open access funding provided by Università degli Studi di Napoli Federico II within the CRUI-CARE Agreement.

Data availability Data will be made available upon reasonable request to the corresponding author.

\section{Declarations}

Ethics approval This study was approved by the local ethical committee 'Carlo Romano'. The study was performed in accordance with good clinical practices and the Declaration of Helsinki.

Consent to participate Each subject involved in the study gave their informed consent prior to their inclusion in the study.

Conflict of interest RL and VBM received personal compensations for speaking or consultancy from Biogen, Teva, Genzyme, Merck, Novartis and Almirall. MM has received salary from Federico II University of Naples, research grants from the ECTRIMS-MAGNIMS, UK and Northern Ireland MS Society and Merck, and honoraria form Biogen, Genzyme, Merck and Roche. AC has received research grants from ALMIRALL, and honoraria form Novartis and Roche. FS has received speaking honoraria from Biogen, Mylan, Novartis, Roche, Sanofi and Teva; served on advisory boards for Almirall, Argenx, Avexis, Biogen, Forward Pharma, Merk, Novartis, Pomona, Roche and Sanofi. $\mathrm{SC}$ has received fees for speaking from Shire and Genzyme and fees for adv. board from Amicus. TC, MP, MP, FF, GP, MDS, CP, TP, EAV and $\mathrm{MBC}$ have nothing to disclose.

Open Access This article is licensed under a Creative Commons Attribution 4.0 International License, which permits use, sharing, adaptation, distribution and reproduction in any medium or format, as long as you give appropriate credit to the original author(s) and the source, provide a link to the Creative Commons licence, and indicate if changes were made. The images or other third party material in this article are included in the article's Creative Commons licence, unless indicated otherwise in a credit line to the material. If material is not included in the article's Creative Commons licence and your intended use is not permitted by statutory regulation or exceeds the permitted use, you will need to obtain permission directly from the copyright holder. To view a copy of this licence, visit http://creativecommons.org/licenses/by/4.0/.

\section{References}

1. Amato MP, Ponziani G, Pracucci G, Bracco L, Siracusa G, Amaducci L (1995) Cognitive impairment in early-onset multiple sclerosis. Pattern, predictors, and impact on everyday life in a 4-year follow-up. Arch Neurol 52(2):168-172. https://doi.org/10.1001/ archneur.1995.00540260072019

2. Chiaravalloti ND, DeLuca J (2008) Cognitive impairment in multiple sclerosis. Lancet Neurol 7(12):1139-1151. https://doi.org/10. 1016/S1474-4422(08)70259-X

3. Lanzillo R, Chiodi A, Carotenuto A, Magri V, Napolitano A, Liuzzi R, Costabile T, Rainone N, Freda MF, Valerio P, Brescia Morra V (2016) Quality of life and cognitive functions in early onset multiple sclerosis. Eur J Paediatr Neurol 20(1):158-163. https://doi.org/10.1016/j.ejpn.2015.08.005
4. Di Filippo M, Portaccio E, Mancini A, Calabresi P (2018) Multiple sclerosis and cognition: synaptic failure and network dysfunction. Nat Rev Neurosci 19(10):599-609. https://doi.org/10.1038/ s41583-018-0053-9

5. Sumowski JF, Benedict R, Enzinger C, Filippi M, Geurts JJ, Hamalainen P, Hulst H, Inglese M, Leavitt VM, Rocca MA, RostiOtajarvi EM, Rao S (2018) Cognition in multiple sclerosis: State of the field and priorities for the future. Neurology 90(6):278-288. https://doi.org/10.1212/WNL.0000000000004977

6. Huijbregts SC, Kalkers NF, de Sonneville LM, de Groot V, Polman CH (2006) Cognitive impairment and decline in different MS subtypes. J Neurol Sci 245(1-2):187-194. https://doi.org/10. 1016/j.jns.2005.07.018

7. Rocca MA, Riccitelli GC, Meani A, Pagani E, Del Sette P, Martinelli V, Comi G, Falini A, Filippi M (2019) Cognitive reserve, cognition, and regional brain damage in MS: A 2 -year longitudinal study. Mult Scler 25(3):372-381. https://doi.org/10.1177/ 1352458517750767

8. Camp SJ, Stevenson VL, Thompson AJ, Ingle GT, Miller DH, Borras C, Brochet B, Dousset V, Falautano M, Filippi M, Kalkers NF, Montalban X, Polman CH, Langdon DW (2005) A longitudinal study of cognition in primary progressive multiple sclerosis. Brain 128(Pt 12):2891-2898. https://doi.org/10.1093/brain/ awh602

9. Zivadinov R, Sepcic J, Nasuelli D, De Masi R, Bragadin LM, Tommasi MA, Zambito-Marsala S, Moretti R, Bratina A, Ukmar M, Pozzi-Mucelli RS, Grop A, Cazzato G, Zorzon M (2001) A longitudinal study of brain atrophy and cognitive disturbances in the early phase of relapsing-remitting multiple sclerosis. J Neurol Neurosurg Psychiatry 70(6):773-780. https://doi.org/10.1136/ jnnp.70.6.773

10. Summers M, Fisniku L, Anderson V, Miller D, Cipolotti L, Ron M (2008) Cognitive impairment in relapsing-remitting multiple sclerosis can be predicted by imaging performed several years earlier. Mult Scler 14(2):197-204. https://doi.org/10.1177/13524 58507082353

11. Deloire MS, Ruet A, Hamel D, Bonnet M, Dousset V, Brochet B (2011) MRI predictors of cognitive outcome in early multiple sclerosis. Neurology 76(13):1161-1167. https://doi.org/10.1212/ WNL.0b013e318212a8be

12. Eijlers AJC, van Geest Q, Dekker I, Steenwijk MD, Meijer KA, Hulst HE, Barkhof F, Uitdehaag BMJ, Schoonheim MM, Geurts JJG (2018) Predicting cognitive decline in multiple sclerosis: a 5-year follow-up study. Brain 141(9):2605-2618. https://doi.org/ 10.1093/brain/awy202

13. Nagin DS, Odgers CL (2010) Group-based trajectory modeling in clinical research. Annu Rev Clin Psychol 6:109-138. https://doi. org/10.1146/annurev.clinpsy.121208.131413

14. Helgeson VS, Snyder P, Seltman H (2004) Psychological and physical adjustment to breast cancer over 4 years: identifying distinct trajectories of change. Health Psychol 23(1):3-15. https:// doi.org/10.1037/0278-6133.23.1.3

15. Weisburd D, Bushway S, Lum C, Yang S-M (2004) Trajectories of crime at places: a longitudinal study of street segments in the city of Seattle*. Criminology 42(2):283-322. https://doi.org/10. 1111/j.1745-9125.2004.tb00521.x

16. Lee JS, Cho SK, Kim HJ, Kim YJ, Park KC, Lockhart SN, Na DL, Kim C, Seo SW (2018) Prediction Models of Cognitive Trajectories in Patients with Nonamnestic Mild Cognitive Impairment. Sci Rep 8(1):10468. https://doi.org/10.1038/s41598-018-28881-1

17. Xie H, Mayo N, Koski L (2011) Identifying and characterizing trajectories of cognitive change in older persons with mild cognitive impairment. Dement Geriatr Cogn Disord 31(2):165-172. https://doi.org/10.1159/000323568

18. Polman CH, Reingold SC, Banwell B, Clanet M, Cohen JA, Filippi M, Fujihara K, Havrdova E, Hutchinson M, Kappos L, 
Lublin FD, Montalban X, O’Connor P, Sandberg-Wollheim M, Thompson AJ, Waubant E, Weinshenker B, Wolinsky JS (2011) Diagnostic criteria for multiple sclerosis: 2010 revisions to the McDonald criteria. Ann Neurol 69(2):292-302. https://doi.org/ 10.1002/ana.22366

19. Polman CH, Reingold SC, Edan G, Filippi M, Hartung HP, Kappos L, Lublin FD, Metz LM, McFarland HF, O'Connor PW, Sandberg-Wollheim M, Thompson AJ, Weinshenker BG, Wolinsky JS (2005) Diagnostic criteria for multiple sclerosis: 2005 revisions to the "McDonald Criteria." Ann Neurol 58(6):840-846. https:// doi.org/10.1002/ana.20703

20. McDonald WI, Compston A, Edan G, Goodkin D, Hartung HP, Lublin FD, McFarland HF, Paty DW, Polman CH, Reingold SC, Sandberg-Wollheim M, Sibley W, Thompson A, van den Noort S, Weinshenker BY, Wolinsky JS (2001) Recommended diagnostic criteria for multiple sclerosis: guidelines from the International Panel on the diagnosis of multiple sclerosis. Ann Neurol 50(1):121-127. https://doi.org/10.1002/ana.1032

21. Benedict RH, DeLuca J, Phillips G, LaRocca N, Hudson LD, Rudick R, Multiple Sclerosis Outcome Assessments C (2017) Validity of the Symbol Digit Modalities Test as a cognition performance outcome measure for multiple sclerosis. Mult Scler 23(5):721-733. https://doi.org/10.1177/1352458517690821

22. Amato MP, Portaccio E, Goretti B, Zipoli V, Ricchiuti L, De Caro MF, Patti F, Vecchio R, Sorbi S, Trojano M (2006) The Rao's Brief Repeatable Battery and Stroop Test: normative values with age, education and gender corrections in an Italian population. Mult Scler 12(6):787-793. https://doi.org/10.1177/1352458506 070933

23. Goretti B, Niccolai C, Hakiki B, Sturchio A, Falautano M, Minacapelli E, Martinelli V, Incerti C, Nocentini U, Murgia M, Fenu G, Cocco E, Marrosu MG, Garofalo E, Ambra FI, Maddestra M, Consalvo M, Viterbo RG, Trojano M, Losignore NA, Zimatore GB, Pietrolongo E, Lugaresi A, Langdon D, Portaccio E, Amato MP (2014) The Brief International Cognitive Assessment for Multiple Sclerosis (BICAMS): normative values with gender, age and education corrections in the Italian population. BMC Neurol 14:171. https://doi.org/10.1186/s12883-014-0171-6

24. Smith SM, Zhang Y, Jenkinson M, Chen J, Matthews PM, Federico A, De Stefano N (2002) Accurate, robust, and automated longitudinal and cross-sectional brain change analysis. Neuroimage 17(1):479-489. https://doi.org/10.1006/nimg.2002.1040

25. Patenaude B, Smith SM, Kennedy DN, Jenkinson M (2011) A Bayesian model of shape and appearance for subcortical brain segmentation. Neuroimage 56(3):907-922. https://doi.org/10. 1016/j.neuroimage.2011.02.046

26. Jones BL, Nagin D (2012) A Stata Plugin for Estimating GroupBased Trajectory Models. Carn Mell Univ J. https://doi.org/10. 1184/R1/6470963.v1

27. Bozdogan H (1987) Model selection and Akaike's Information Criterion (AIC): The general theory and its analytical extensions. Psychometrika 52(3):345-370. https://doi.org/10.1007/bf022 94361

28. Jones BL, Nagin DS, Roeder K (2001) A SAS Procedure Based on Mixture Models for Estimating Developmental Trajectories. Sociol Methods Res 29(3):374-393. https://doi.org/10.1177/ 0049124101029003005

29. Whitehouse CE, Fisk JD, Bernstein CN, Berrigan LI, Bolton JM, Graff LA, Hitchon CA, Marriott JJ, Peschken CA, Sareen J, Walker JR, Stewart SH, Marrie RA, Burden CTiDt, Managing the
Effects of Psychiatric Comorbidity in Chronic Immunoinflammatory D (2019) Comorbid anxiety, depression, and cognition in MS and other immune-mediated disorders. Neurology. https://doi.org/ 10.1212/WNL.0000000000006854

30. Healy BC, Barker L, Bakshi R, Benedict RHB, Gonzalez CT, Chitnis T, Weiner HL, Glanz BI (2020) Trajectories of Symbol Digit Modalities Test performance in individuals with multiple sclerosis. Mult Scler 1352458520913439. https://doi.org/10.1177/ 1352458520913439

31. Damasceno A, Pimentel-Silva LR, Damasceno BP, Cendes F (2019) Cognitive trajectories in relapsing-remitting multiple sclerosis: a longitudinal 6-year study. Mult Scler 1352458519878685. https://doi.org/10.1177/1352458519878685

32. Amato MP, Portaccio E, Goretti B, Zipoli V, Battaglini M, Bartolozzi ML, Stromillo ML, Guidi L, Siracusa G, Sorbi S, Federico A, De Stefano N (2007) Association of neocortical volume changes with cognitive deterioration in relapsing-remitting multiple sclerosis. Arch Neurol 64(8):1157-1161. https://doi.org/10. 1001/archneur.64.8.1157

33. Benedict RH, Holtzer R, Motl RW, Foley FW, Kaur S, Hojnacki D, Weinstock-Guttman B (2011) Upper and lower extremity motor function and cognitive impairment in multiple sclerosis. J Int Neuropsychol Soc 17(4):643-653. https://doi.org/10.1017/ S1355617711000403

34. Eijlers AJC, Dekker I, Steenwijk MD, Meijer KA, Hulst HE, Pouwels PJW, Uitdehaag BMJ, Barkhof F, Vrenken H, Schoonheim MM, Geurts JJG (2019) Cortical atrophy accelerates as cognitive decline worsens in multiple sclerosis. Neurology 93(14):e1348 e1359. https://doi.org/10.1212/WNL.0000000000008198

35. Benedict RH, Ramasamy D, Munschauer F, Weinstock-Guttman B, Zivadinov R (2009) Memory impairment in multiple sclerosis: correlation with deep grey matter and mesial temporal atrophy. $\mathrm{J}$ Neurol Neurosurg Psychiatry 80(2):201-206. https://doi.org/10. 1136/jnnp.2008.148403

36 Rocca MA, Barkhof F, De Luca J, Frisen J, Geurts JJG, Hulst HE, Sastre-Garriga J, Filippi M, Group MS (2018) The hippocampus in multiple sclerosis. Lancet Neurol 17(10):918-926. https://doi. org/10.1016/S1474-4422(18)30309-0

37. Stern Y (2012) Cognitive reserve in ageing and Alzheimer's disease. Lancet Neurol 11(11):1006-1012. https://doi.org/10.1016/ S1474-4422(12)70191-6

38. Barbarulo AM, Lus G, Signoriello E, Trojano L, Grossi D, Esposito M, Costabile T, Lanzillo R, Sacca F, Morra VB, Conchiglia G (2018) Integrated cognitive and neuromotor rehabilitation in multiple sclerosis: a pragmatic study. Front Behav Neurosci 12:196. https://doi.org/10.3389/fnbeh.2018.00196

39. Prosperini L, Piattella MC, Gianni C, Pantano P (2015) Functional and structural brain plasticity enhanced by motor and cognitive rehabilitation in multiple sclerosis. Neural Plast 2015:481574. https://doi.org/10.1155/2015/481574

40. Iodice R, Manganelli F, Dubbioso R (2017) The therapeutic use of non-invasive brain stimulation in multiple sclerosis - a review. Restor Neurol Neurosci 35(5):497-509. https://doi.org/10.3233/ RNN-170735

Publisher's note Springer Nature remains neutral with regard to jurisdictional claims in published maps and institutional affiliations. 